\title{
PREVALENCE OF EIMERIA SCHNEIDER, 1875 IN LAYER CHICKEN OF SOME POULTRY FARMS OF KATHMANDU AND LALITPUR DISTRICTS
}

\author{
RAKESH PRASAD JAYSWAL ${ }^{1} \bowtie$, RANJANA GUPTA $^{2}$ AND \\ SWOYAM PRAKASH SHRESTHA ${ }^{3}$
}

\author{
${ }^{1}$ Tri-Chandra Campus, Tribhuvan University, Kathmandu, Nepal \\ ${ }^{2}$ Central Department of Zoology,T.U. Kirtipur, Kathmandu Nepal. \\ ${ }^{3}$ Animal Health Research Division \\ NARC, Khumaltar, Lalitpur,Nepal \\ rakeshjayswal@yahoo.com
}

\section{ABSTRACT}

In the present study five Eimeria species viz. Eimeria tenella, E. acervulina, E. necatrix, E. maxima and $E$. brunetti responsible for coccidiosis are reported and its general prevalence was found to be 24 percent. Among the five Eimeria species, prevalence of $E$. tenella was recorded to be the highest (25\%), followed by E. acervulina (15\%), E. necatrix (10\%). E. maxima (7\%) and E. brunetti (3\%).

Altogether 400 stool samples (dropping) were collected by random sampling methods from four poultry farms. These samples were preserved in preservative solution $(2 \%$ potassium dichromate solution). Stool samples were examined by thin feacal smear methods. There were altogether 96 cases of coccidiosis of which $25 \%$ were caecal, $35 \%$ intestinal and $40 \%$ mixed. Prevalence of coccidiosis was recorded in all the 12 months and four seasons of the study period. The highest (38\%) prevalence rate was found in the month of July and the lowest $(5.71 \%)$ in the month of October. The difference in monthly prevalence of Eimeria was insignificant $\left(x^{2}=19.675, \mathrm{P}<0.05\right)$. Similarly season wise prevalence showed the highest $(35 \%)$ prevalence rate in the spring season followed by summer (25\%), winter (23\%) and autumn (12\%). Seasonwise difference in prevalence of Eimeria was found to be insignificant $\left(x^{2}=7.815, P>0.05\right)$. The age- wise prevalence was the highest (34.66\%) in 61 weeks above chicken, followed by $30 \%$ in the $46-60$ weeks age group, $22.5 \%$ in the $31-45$ weeks age group, $17.14 \%$ in the $0-15$ weeks age group and $15.78 \%$ in the $16-30$ weeks age group. The difference in age- wise prevalence was found to be insignificant $\left(x^{2}=9.488, P>0.05\right)$.

Keywords: Coccidiosis, feacal smear, Gallus

\section{INTRODUCTION}

In Nepal, poultry farming is one of the commercial branch of agriculture practices. It is the main source of livelihood both in the rural and urban farming communities. The egg is also rich in vitamins like $A, D, B_{1}, B_{2}$ and pantothenic acid. The chicken meat contains a high quality of thiamine, riboflavin and pantothenic acid (Naidu, 1967). 
The Layer chicken is commercially developed for egg production; about 300 to 330 eggs are produced by Layer per annum up to 72 weeks of age. The common breeds of Layer chicken in Nepal are Keystone, Hyaline, Astrolop, New Ham share and Babcock.

Infection with a sing le species of coccidia are rare in natural conditions, mixed infection being the rule; Eimeria species infections are ubiquitous and the limit to their distribution is the host (Jordan \& Pattion, 1996). The species of Eimeria are identified on the morphological basis taking in view of their shape, size and internal structure. In the host, the parasite grows and multiplies intracellular in epithelial and sub- epithelial cell of the gut wall (Gordan \& Jordan, 1982).

Ingestion of viable sporulated oocysts through contaminated feed and water is only natural method of transmission. Human are second in transport and dissemination of oocysts to chicken. Mechanical transmission is commonly affected by manure clinging to shoes or by fomites from one person to another. Coccidia are cosmopolitan in distribution (Hufshed, 1992). In the external environment, the limit of factors for survival of oocysts include the presence of oxygen, water and suitable temperature. Infected chicken discharge large number of oocysts in their droppings in the fresh state.

Sporulation takes one or two days under optimum temperature of $25^{\circ} \mathrm{C}$ to $32^{\circ} \mathrm{C}$ with high humidity. Coccidiosis can occur at any stage of life and any season when condition are favorable. Day old chicken are susceptible to coccidiosis but may develop minimal infections because occysts are not excysted in very young chicken (Rose, 1967).

The disease is likely to occur only under condition of high stocking density and unhygienic environment. Coccidiosis is one of the important diseases in intensive farming system (Urguhart,1987).

\section{MATERIALS AND METHODS}

Four hundred droppings (stool samples) of fowls (Gallus domesticus) were collected by random sampling method from four poultry farms from Machhegaun, Futung, Gothatar of Kathmandu district and Khumaltar of Lalitpur disrict during June 2009 to May 2010 and Khumaltar of Lalitpur disrict. The stools were preserved in $2 \%$ potassium dichromate solution and were later examined by thin feacal smear method. For detailed morphological study of oocysts, they were cultured (sporulated) in the laboratory. For this, these droppings were kept in $2 \%$ potassium dichromate solution in the ratio of 1:5 (1 part dropping and 5 parts of potassium dichromate solution) under aerobic condition at room temperature. These sporulated oocysts were examined under microscope and their shape and size were observed. The size of the sporulated oocysts was measured using a calibrated eyepiece micrometer under microscope at 100x magnification. The size (length and width) and shape of about 10 sporulated oocysts from each positive sample were recorded for identification of Eimeria species. Oocysts were identified by studying the morphological characters given by Long \& Reid (1982).

\section{RESULTS}

\section{General prevalence of coccidiosis}

The total number of dropping examined were 400 of which coccidiosis positive samples were 96. Hence the prevalence of coccidiosis was found to be $24 \%$. 


\section{Month-wise prevalence}

The month- wise prevalence of coccidiosis with respect to temperature, relative humidity and rainfall in one year period has been presented in fig. 1 . The prevalence of coccidiosis was high $(38 \%)$ in rainfall $544.80 \mathrm{~mm}$, relative humidity 85.45 precent and temperature $24.50^{\circ} \mathrm{C}$ in the month of July. Then there was a gradual decrease in the prevalence rate of coccidiosis from August to October. The lowest prevalence rate was in the month of October $(5.71 \%)$ in rainfall $15.00 \mathrm{~mm}$, relative humidity 82.70 percent and temperature $20.10^{\circ} \mathrm{C}$. From November on wards the prevalence rate increased slightly. The Chi-square test indicated that the difference in monthly prevalence of coccidiosis was insignificant $\left(x^{2}=19.675, P<0.05\right)$.

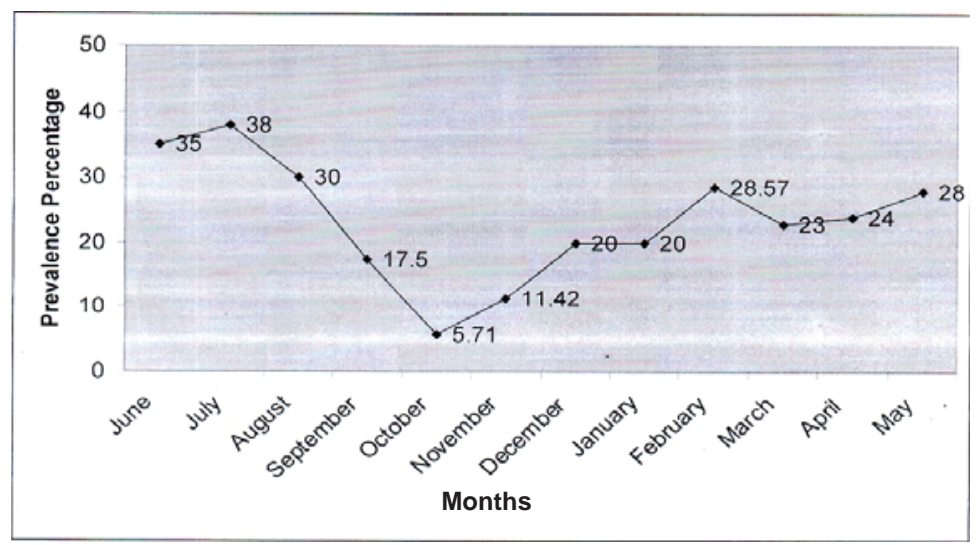

FIG. 1. Month-wise prevalence of coccidiosis in Kathmandu and Lalitpur districts.

\section{Season-wise prevalence of coccidiosis in layer chicken}

The prevalence of coccidiosis was the highest during spring (rainy) season (35\%) and the lowest during autumn season (12\%). The prevalence of coccidiosis in the winter and summer gradually increased with $23 \%$ and $25 \%$ respectively. Statistically, the difference in season-wise prevalence of coccidiosis was found to be insignificant $\left(x^{2}=.815, P>0.05\right)$.

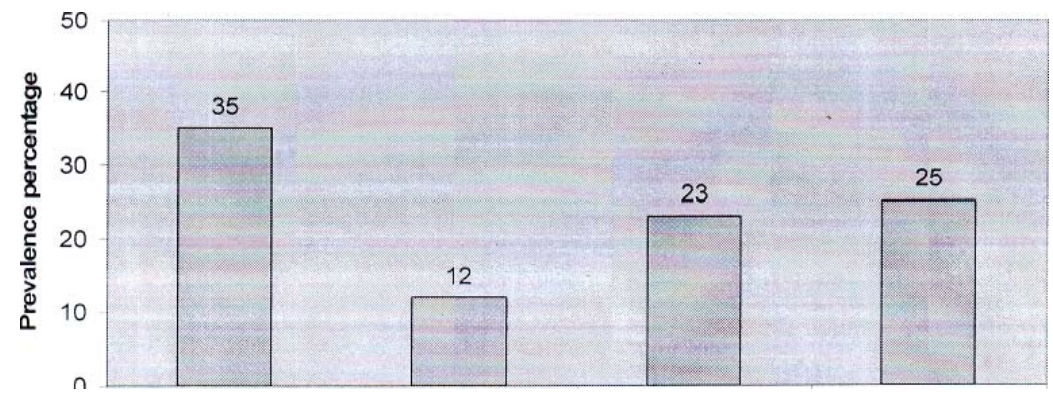

Spring (rainy) (June- Aug.) Autum (Sep.-Nov) Winter (Dec-Feb.) Summer (March-May) 


\section{Age-wise prevalence of coccidiosis in Layer Chicken}

The age group of studied Layer chicken were categorized into difference of 15 weeks, up to 61 weeks and above. The prevalence of coccidiosis was the highest in 61 and above week age group of Layers (34.66\%). The lowest prevalence of coccidiosis was in 16 to 30 weeks age group of Layers (15.78\%). The mortality rate was found to be high in Layers of $0-15$ weeks age group. The prevalence rate of coccidiosis in Layers gradually increased from $22.5 \%$ in 31 to 45 weeks age group up to $34.66 \%$ in 61 - above age group. Statistically the difference in age-wise prevalence of coccidiosis was insignificant $\left(x^{2}=9.488, P>0.05\right)$.

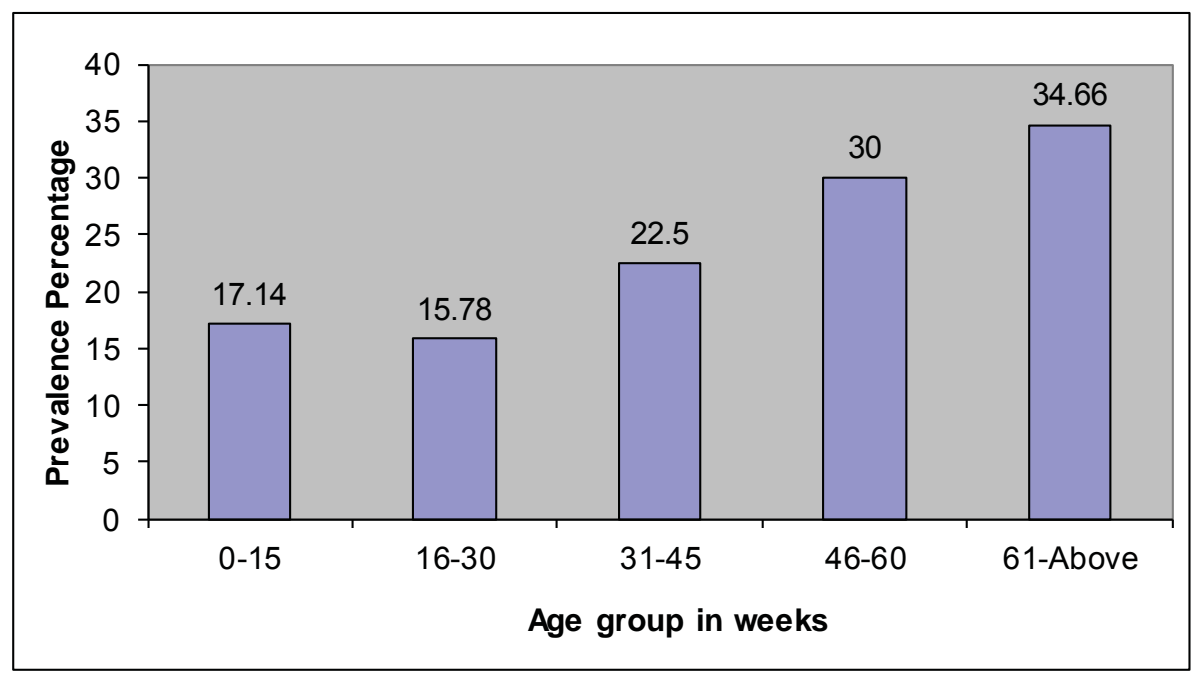

FIG.3. Prevalence of coccidiosis in different age of Layer chicken.

\section{Identification of different species of Eimeria in Layer Chicken}

Eimeria species were identified by the examination of gross lesions, caecal and intestinal scrapings and oocysts of morphological shape, size and internal structure. Each species has its own specific site of invasion in the intestine of chicken. E. tenella attack the double caeca, while $E$. acervulina affect the double portion of intestine. Similarly E. necatrix and E. maxima affect the major portion of the small intestine. Altogether 5 different Eimeria species were observed. They were E. tenella, E.acervulina, E. necatrix, E. maxima, E. brunetti. 


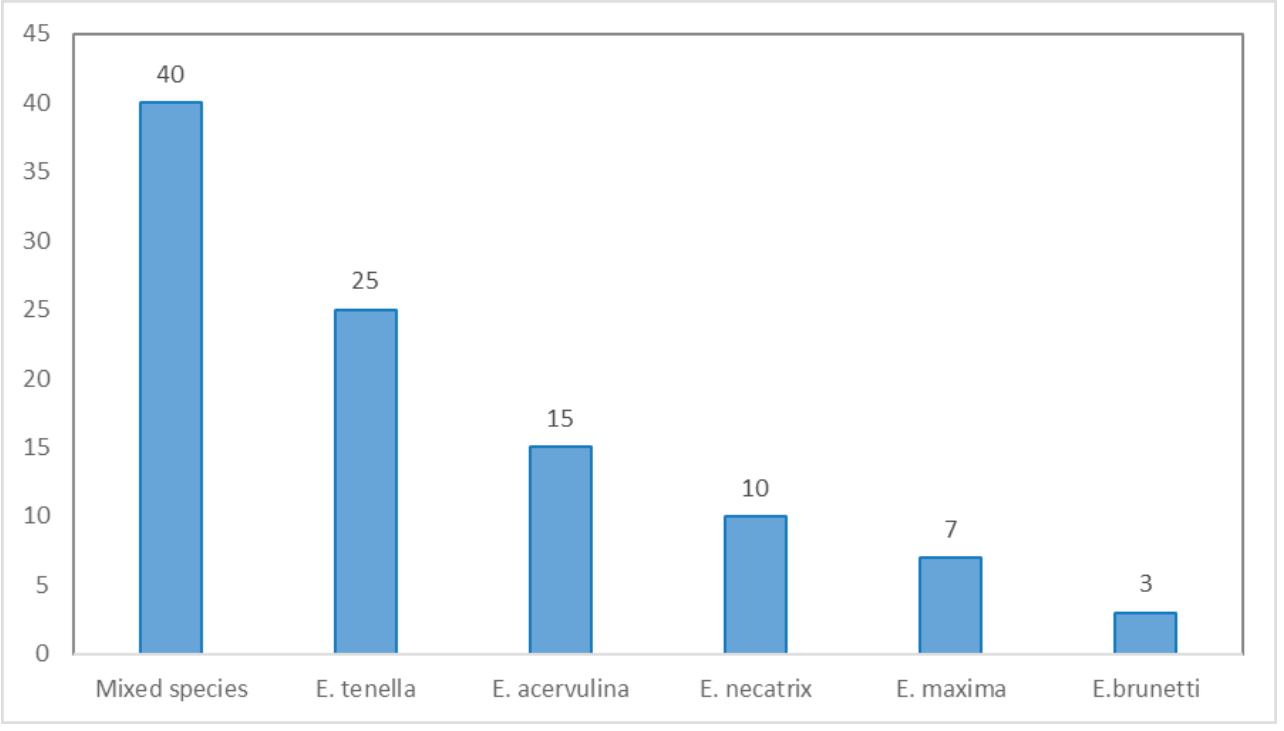

FIG. 4. Prevalence of different Eimeria species in Layer chicken.

Microphotographs showing different Species of Eimeria at 400X magnification

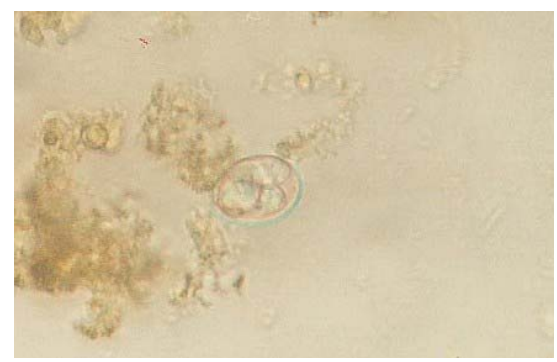

Plate 11. Oocyst of E. tenella

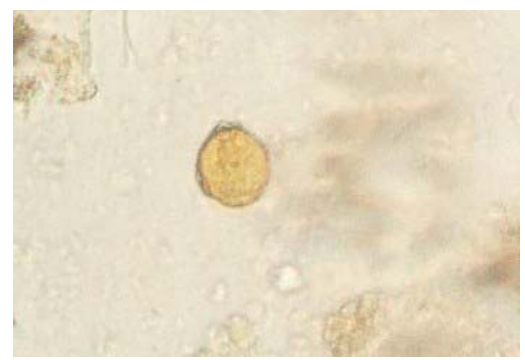

Plate 12. Oocyst of $E$. acervulina

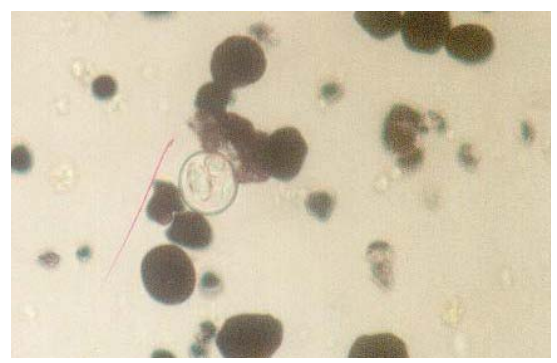

Plate 13. Oocyst of E.necatrix

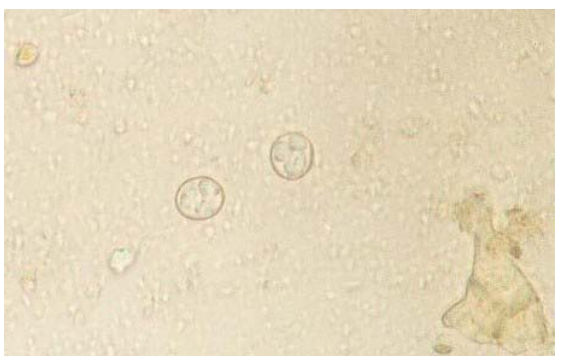

Plate 14. Oocyst of E.maxima 


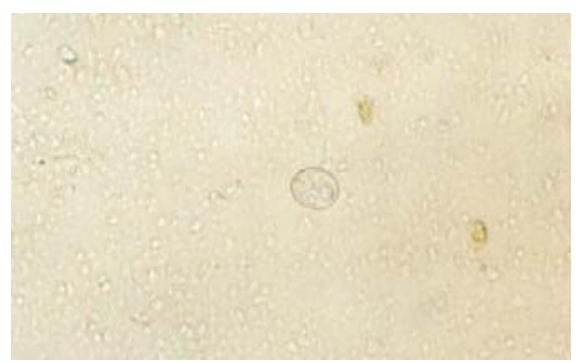

Plate 15. Oocyst of E.burnetti

\section{DISCUSSION}

Coccidiosis is one of the main problem in poultry farming in Nepal. Eimeria species is the main causative agent of coccidiosis, which widely occurs through out Nepal. Heavy morbidity and mortality due to coccidiosis have significantly affected the poultry industry. In the present study the prevalence rate of coccidiosis was found to be $24 \%$. Altogether 5 species of Eimeria are reported.

These identified Eimeria species have been reported earlier by Thakuri \& Rai (1996), in the local chickens of eastern hills of Nepal except E. necatrix. It is correlated to the report mentioned in Bangladesh by Karim \& Begum (1994), in Sweden by Thebo et al. (1998), and in Rampur, Nepal and its vicinity by Aryal (2001). The findings agree with the statement made by Macpherson (1978), that the same species of Eimeria all over the world will infect domestic poultry. The morphological (shape and size) characteristics, location and nature of intestinal lesions correspond to the description made by Gordon \& Jordon (1982), and earlier works.

The monthly prevalence found in the present study was highest (38\%) in the month of July, with the average temperature $24.50^{\circ} \mathrm{C}$ and rainfall $544.80 \mathrm{~mm}$ and humidity 85.45 . The lowest prevalence was found in the month of October $(5.71 \%)$ with the average temperature $20.10^{\circ} \mathrm{C}$ and rainfall $15.00 \mathrm{~mm}$. The month-wise study carried out by Chio et al. (1986) showed that the highest prevalence rate of coccidiosis was $50 \%$ in the months of March and June, respectively. The high prevalence rate of coccidiosis might be due to effect of favorable environment for the sporulation of oocysts.

The seasonal prevalence found in this study was the highest (35\%) during spring (rainy) season with temperature 25 to $30^{\circ} \mathrm{C}$, rainfall 544.80 to $499.90 \mathrm{~mm}$ and humidity 85.70 to 79.50 , which helped to increase the sporulation rate of the oocysts. The lowest prevalence was recorded during autumn (12\%). Hence the factors effecting coccidiosis during autumn was found to be unfavorable. The finding of Basisth and Rajavelu (2000) in Tamil Nadu, India showed that the season-wise prevalence rate of coccidiosis was the highest (33\%) during summer season and lowest (14\%) during autumn season in Layer flock.

The age-wise highest prevalence of coccidiosis was found in the 61-above week age group $(34.66 \%)$ chronically affected with high morbadity and less mortality. This might be associated with crowding factor and loss of immunity power. The mortality rate was found to be high 
between (0-15) weeks age group. Lower prevalence rate (15.78\%) in (16-30) weeks age group might be associated with time and immune status. The study reported by Panda et al. (1997) in India revealed that the prevalence rate of coccidiosis was highest (48\%) in Layer of 31-45 days age group than that of $0-15$ days age group (6\%).

\section{ACKNOWLEDGEMENTS}

Authors thank the staffs of Central Veterinary Laboratory, Tripureswor, Kathmandu and Animal Health Research Division (NARC) Khumaltar, Lalitpur, for providing necessary Lab facilities. Thanks are also to the poultry farmers of Machhegaun, Futung, Gothatar and Khumaltar areas for their co-operation in the field study.

\section{REFERENCES}

ARYAL, M P (2001) Epidemiological study on Eimeria species in natural outbreak of chicken coccidiosis at IAAS Ram pur and its vicinity. Advances in Agricultural Research in Nepal at Society of Agricultural Scientists (SAS), Nepal 168-175.

BASIST, S A; RAJAVELU, G (2000) Seasonal prevalence of coccidiosis in chicken at Namakkal (Tamil Nadu). Indian Veterinary Journal 77: 163-164.

CHIO, S H; KIM, K S; KIM, Y H (1986) Epizootiology study on the coccidiosis of layer chicken in Korea. Res Rep off Rural Dev. (Livest vet) Suwen, 26(2): 44-52.

GORDON, R F; JORDAN, F T W (1982) Poultry diseases. Bailliere Tindall; pp. 69-177 (2nd edition).

HUFSHED, M S (1992) Diseases of poultry. Parima Educational Book Agency, New Delhi; pp. 691-708 (8th edition).

JORDAN, F T W; PATTISON, M (1996) Poultry diseases. W.B. Saunders Company LTD. London NW I7DX (4th edition).

KARIM, M D J; BEGUN, N (1994) Morphological and biological characterization of chicken Eimeria with special reference to species identification. Vet. Review 9(1) and 10(1): 7-9.

LONG, P L; REID, W M (1982) Research report 404, College of Agricultural Experiment Station; University of Georgia, USA.

MACPHERSON, I (1978) Avian coccidiosis. British Poultry Science Ltd.Edinburgh, Scotland; pp. 465-494.

NAIDU, P M N (1967) Poultry keeping in India. Indian Council of Agriculture Research 4(7): 36-37.

PANDA, D N; MISHRA, A; MISHRA, S C; PANDA, B K (1997) Incidence of coccidiosis in layer chicken in and around Bhubaneswar, Orrisa. Indian Veterinary Journal 74: 430-431.

ROSE, M E (1967) The influence of age of host on infection with Eimeria tenella. J. Parasilol 53: 924-929.

THAKURI, K C; RAI, K (1996) Identification of Eimeria species found in local chicken of eastern hills of Nepal. Veterinary Review 9( 1): 5-6.

THEBO, P; LUNDEN, A; UGGLA, A; HOOSHMAND, R P (1998) Identification of seven Eimeria species in Swedish domestic fowl. Avian Pathology 27(6): 613-617.

URGUHART, G M (1987) Veterinary Parasitology. Longman Scientific and Technical, Longman Group, UK Limited, Essex CM 202 JE, England; pp. 221-223. 